\title{
Molecular Identification of a Sexual Interloper: The Pear Pathogen, Venturia pirina, has Sex on Apple
}

\author{
Christiane Stehmann, Shaun Pennycook, and Kim M. Plummer
}

First and second authors: HortResearch, Mt. Albert Research Centre, 120 Mt. Albert Rd., Private Bag 92169, Auckland, New Zealand; and third author: The University of Auckland, School of Biological Sciences, Private Bag 92019 New Zealand. Accepted for publication 23 March 2001.

\section{ABSTRACT}

Stehmann, C., Pennycook, S., and Plummer, K. M. 2001. Molecular identification of a sexual interloper: The pear pathogen, Venturia pirina, has sex on apple. Phytopathology 91:633-641.

Venturia pirina (the pear scab pathogen) and V. inaequalis (the apple scab pathogen) were detected as ascospores discharged from apple leaf litter in New Zealand (spring 1998). Pseudothecia of both species were located on dead apple leaves; however, only those of $V$. inaequalis were associated with scab lesions. V. pirina was identified by rDNA sequence analyses, because morphological characters could not distinguish this fungus from $V$. asperata (a rare saprophyte on apple) and other Venturia spp. pathogenic on rosaceous fruit trees. Species-specific polymerase chain reaction primers designed to the $18 \mathrm{~S}$ end of the internal transcribed spacer 1 region differentiated Venturia fruit tree pathogens reliably. $V$. pirina field isolates were pathogenic on pear, but only weak saprophytes on apple. In rare instances, when appressoria of $V$. pirina appeared to penetrate the cuticle of apple leaves, epidermal cells responded with a localized hypersensitive response (HR). To our knowledge, this is the first report of induction of HR-like events by $V$. pirina on its nonhost, apple, and also the first record of sexual reproduction of $V$. pirina on apple. It is assumed that $V$. pirina pseudothecia formed from saprophytic lesions in senescing apple leaves when active defense mechanisms such as HR were no longer induced.

Additional keywords: disease prediction, molecular species identification, nonhost resistance, phylogenetic analysis.
Scab, caused by the ascomycete Venturia inaequalis (Cooke) G. Wint., is an economically important fungal disease of apple (Malus spp.). It occurs worldwide where apple is grown and is a serious problem in temperate regions with cool, moist climates in early spring (26). The main strategies used for scab control are frequent applications of fungicides and the use of scab-resistant apple cultivars $(14,24)$; however, selection pressure has resulted in the evolution of fungicide and cultivar resistant races (26). To date, apple-breeding programs have focused on introgressing major disease resistance genes from wild Malus germ plasm into apple breeding lines and commercial cultivars $(10,18,40)$. Major resistance genes (e.g., Vf) can be broken by races of $V$. inaequalis (30). The selection of cultivar resistant races has been reported in other plant-pathogen systems $(22,33)$ and other avenues for more durable resistance such as gene pyramiding and the use of novel resistance genes are currently under investigation $(11,19,32)$.

Scab diseases of other rosaceous fruit tree species are also caused by species of the genus Venturia (37). Phylogenetic relationships within the Venturia spp. and their hosts, based on rDNA (internal transcribed spacer [ITS]; ITS1-5.8S-ITS2) sequence polymorphisms, have been interpreted as evidence for coevolution of these pathogens with their respective hosts $(8,36): V$. pirina/ $V$. nashicola and pear (Pyrus spp.); and V. carpophila, V. cerasi, and stone fruit (Prunus spp.; peach/nectarine and cherry, respectively). A long history of association between host and pathogen is thought to lead to coadaptation as well as cospeciation. This is the case in a number of plant-pathogen interactions $(3,17,27)$. A

Corresponding author: K. M. Plummer; E-mail address: kplummer@hortresearch.co.nz

* The $e$-Xtra logo stands for "electronic extra" and indicates the HTML abstract available on-line contains supplemental material not included in the print edition. Figures 2, 4, and 8 are in color on-line.

Publication no. P-2001-0509-01R

(C) 2001 The American Phytopathological Society thorough understanding of the genetic basis in these host-parasite associations is essential for assessing breeding strategies and predicting durability of resistance. In this context, Venturia spp. on rosaceous fruit tree species present a good model for investigating the limitations and determinants of host range.

Venturia spp. are hemibiotrophic pathogens. In the biotrophic (anamorph) stage, subcuticular mycelia invade developing leaves and fruit and proliferate via sporulation structures that emerge through the plant cuticle. During this parasitic stage, Venturia spp. can only infect a relatively narrow spectrum of hosts (i.e., genusspecific). As pathogens of deciduous trees, these fungi have adapted to overwinter as saprophytes, forming pseudothecia (teleomorph/sexual stage) in late winter in the leaf litter. The sexually produced ascospores are the primary inoculum that infect young leaves in spring. Therefore, disease-forecasting systems for apple scab, which are based on climate conditions conducive to ascospore release and infection, have been designed in order to optimize fungicide applications (2). During an epidemiological study from August to December 1998, ascospores of V. inaequalis and a second unidentified Venturia sp. were detected as discharge from apple leaf litter originating from an organic orchard in Hawkes Bay, New Zealand (NZ). To this date, only one other Venturia sp., V. asperata, has been recorded to produce sexual spores on apple $(9,35)$; however, its pathogenicity on apple has never been established. Morphological and molecular characters confirm the status of $V$. inaequalis and $V$. asperata as different species and indicate a close relationship between $V$. asperata and the stone fruit pathogen, V. carpophila $(35,36)$.

Venturia spp. are commonly identified on the basis of morphological characters, i.e., form and arrangement of sexual and asexual spores, which in many cases are absent or ambiguous $(37,38)$. Identification of Venturia spp. that infect fruit trees is also aided by the relatively narrow host specificity of these pathogens during the biotrophic phase $(37,38)$. Molecular characters, such as rDNA sequence polymorphisms, have been used previously to assess 
phylogenetic relationships within the genus Venturia (36) and population diversity within the species $V$. inaequalis $(39,41)$. DNA sequence analysis of rRNA genes and ITS regions is considered one of the most reliable methods for determination of phylogenetic relationships and has been applied frequently in a wide range of organisms $(1,6,21)$. The technique is sensitive and needs minimal tissue. DNA can even be amplified from a smear of material on a microscope slide (45). The coding rDNA sequences evolve relatively slowly and are useful for studying distantly related organisms, whereas the noncoding rDNA ITS sequences evolve more quickly and vary among species and populations (25). These ITS sequences are assumed to change only by random mutation with subsequent genetic drift, making them ideal "molecular clocks" for phylogenetic examination of species and genera.

This paper describes the use of rDNA sequence polymorphisms to aid in the identification of Venturia spp., in particular to identify Venturia spp. detected as sexual spores discharged from apple leaf litter. In addition, the pathogenicity of these Venturia field strains isolated from apple leaf litter is characterized and discussed in view of new resistance breeding strategies.

\section{MATERIALS AND METHODS}

Isolation and detection of field isolates of Venturia. Apple leaf litter with visible $V$. inaequalis lesions was collected shortly after leaf fall from a single cultivar (Braeburn) in a single heavily infected block on an organic orchard in Hawkes Bay, NZ, in June 1998. The leaf litter was prepared for use in the exposed glass slide method, which is designed to ascertain the relative pattern of ascospore discharge over time. Leaf meshes measuring $35 \times 25 \mathrm{~cm}$ were prepared, consisting of a single layer of apple leaves held between two layers of chicken wire netting. Care was taken to preserve the orientation of each leaf so the uppermost surface at the time of collection remained uppermost. The leaf meshes were distributed to five different NZ apple-growing districts (Auckland, Gisborne, Hawkes Bay, Nelson, and Central Otago), where they were overwintered on the ground on a layer of nylon gauze (to reduce accessibility to invertebrate litter feeders). Ascospore release from the leaf meshes was monitored from August/ September to December 1998 (with start dates appropriate to the different site climates). Glass microscope slides $(76 \times 26 \mathrm{~mm})$ were positioned randomly on the leaf meshes; their positions were maintained throughout the monitoring period by use of slide holders spiked into the ground. At each site, either 10 or 15 replicate slides were exposed for 3 to 7 days before fresh slides were substituted in the identical positions. Retrieved slides were air dried, cleared of adhering debris, and mounted in lactophenol cotton blue with coverslips $(60 \times 22 \mathrm{~mm})$. Venturia ascospores were counted at $\times 300$ magnification on three fixed transects per slide. The transects were $5 \mathrm{~mm}$ apart, and each scanned a width of $\approx 450 \mu \mathrm{m}$ running the full length of the coverslip, i.e., an area of

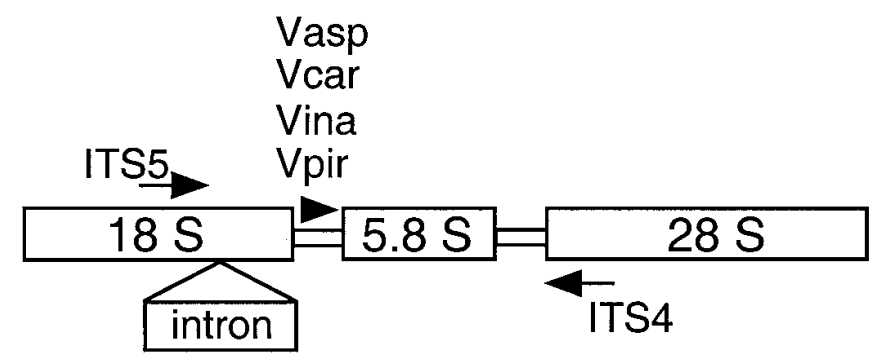

Fig. 1. Map of the ribosomal DNA repeat coding regions $18 \mathrm{~S}, 5.8 \mathrm{~S}$, and $28 \mathrm{~S}$ separated by noncoding internal transcribed spacer (ITS) regions ITS1 and ITS2 (not drawn to scale) showing the location of primers used to amplify and sequence rDNA fragments. The intron in $18 \mathrm{~S}$ has only been reported for Venturia inaequalis. $\approx 27 \mathrm{~mm}^{2}$. Ascospore counts for each transect were transformed to square roots, averaged, and back-transformed to provide a mean count for each slide. Transects in which few ascospores were detected during the entire observation period were omitted from the final analysis.

Venturia isolates were obtained from leaves removed from the periphery of the leaf meshes overwintered in Central Otago. After the leaves had been rehydrated, pseudothecia were excised under the dissecting microscope. Some pseudothecia were squashed for microscopic examination, to determine the morphology of the ascospores and their orientation within the ascus, and adjacent pseudothecia were positioned underneath water agar plates. Sixtytwo ascospores of unidentified field strains ejected from pseudothecia and collected from apple leaf litter (CSS 1.1 to CSS 1.37, CSS 2.1 to CSS 2.4, and CSS 3.1 to CSS 3.21) were isolated from three separate leaves. Single germinating ascospores were transferred from the water agar plates to be cultured on malt extract agar (MEA).

Reference strains and culture conditions. Reference strains of Venturia spp. were obtained from the American Type Culture Collection (ATCC, Maryland) and the International Collection of Micro-Organisms from Plants (ICMP, Landcare, Mount Albert, Auckland, NZ) as lyophilized fungal mycelium: V. pirina isolates ICMP 11032 and 11033 isolated from pear in Hastings, NZ, in 1990, V. carpophila isolate ICMP 5402 isolated from nectarine in the United States, and V. asperata isolates ATCC 34052 and ICMP 13990 to 13993 all collected in NZ in 1974 from apple leaf litter. V. inaequalis isolate MNH 120 was isolated from 'Granny Smith' leaves in 1996 at HortResearch, Auckland, NZ. To ensure genetic purity of the culture, all fungal isolates used in this study were cultured from a single conidium, ascospore, or hyphal tip (where sporulation did not occur).

Isolates were grown as lawn cultures for production of conidia and hyphal mass on potato dextrose agar (PDA) at $18^{\circ} \mathrm{C}$. For longterm storage, lawn cultures on PDA were overlaid with a single layer of sterile antibiotic test disks (Whatman International Ltd., Maidstone, UK). After 14 days, the disks were moved to a sterile petri dish and dried in a desiccator under vacuum for 2 days. The impregnated disks were stored at $-20^{\circ} \mathrm{C}$ until required. Mass production of mycelia was achieved with liquid cultures. Conical flasks $(250 \mathrm{ml})$ containing $100 \mathrm{ml}$ of potato dextrose broth were inoculated with mycelia from 3-week-old lawn cultures and incubated at $18^{\circ} \mathrm{C}$ under continuous shaking for 3 weeks. Mycelia were harvested by filtration through a double layer of Miracloth (Calbiochem, La Jolla, CA).

Pathogenicity assays. Pathogenicity tests were performed with fresh, detached apple (Malus $\times$ domestica cv. Braeburn) and pear (Pyrus communis cv. Winter Nellis open pollinated seedlings) leaves. Apple leaves were inoculated with conidia from 3-weekold lawn cultures of $V$. inaequalis isolate MNH 120 or unknown field isolates CSS 1.12, CSS 1.22, CSS 2.1, and CSS 3.15 at a concentration of $3 \times 10^{4}$ conidia per $\mathrm{ml}$. Pear leaves were inoculated with conidia of CSS 1.12 and a $V$. pirina reference strain from our own laboratory, P3.1.

Inoculated leaves were incubated at $18^{\circ} \mathrm{C}$ for 8 to 10 days. For each fungal isolate, five young (barely unfurled) leaves were harvested, washed thoroughly in sterile water, and left to dry in a laminar flow hood. Leaves were transferred to petri dishes lined with moist filter paper. Leaves were inoculated with 3 to $510-\mu \mathrm{l}$ droplets of conidial suspension or sterile water (control) on the adaxial leaf surface. The left side of each leaf was inoculated with water, and the right side of the same leaf was inoculated with conidial suspension. Leaves were evaluated for visible symptoms after 8 days incubation at $18^{\circ} \mathrm{C}(8 \mathrm{~h}$ light) with a dissecting microscope, and inoculation and control sites were excised and stained in aniline blue for UV-microscopy (7). Leaf pieces were mounted with the adaxial leaf surface facing up on microscope slides in Hoyer's medium (12). For microscopic evaluation, a photo- 
microscope (Vanox; Olympus Optical Co. Ltd., Tokyo, Japan) equipped for epifluorescence with a interference blue filter (excitation 450 to $495 \mathrm{~nm}$, emission over $515 \mathrm{~nm}$ ) was used. Dense sporulation was taken as evidence of a compatible infection.

DNA extraction. Genomic DNA was extracted according to a modified method of Yoder (46). Harvested and washed mycelia from liquid culture were snap frozen in liquid nitrogen and stored at $-80^{\circ} \mathrm{C}$ until required. For DNA extractions, frozen mycelia were freeze dried (Multi-Dry Freeze Dryer; FTS Systems Inc., Stone Ridge, NY) for $48 \mathrm{~h}$ and used immediately. The freeze-dried mycelium was ground to a powder in liquid nitrogen with a mortar and pestle with $1 \mathrm{~g}$ of acid-purified sand. The powder was suspended in $15 \mathrm{ml}$ of extraction buffer $(150 \mathrm{mM}$ EDTA, $50 \mathrm{mM}$ Tris- $\mathrm{HCl}, \mathrm{pH} 8.0$, and $1 \% \mathrm{~N}$-lauroyl-sarcosine) and briefly vortexed. The suspension was centrifuged for $10 \mathrm{~min}$ at $2,900 \times \mathrm{g}$. The resulting supernatant was incubated with proteinase $\mathrm{K}(750 \mu \mathrm{g})$ and RNase A (1 mg) (Sigma Chemical Co., St. Louis) for $2 \mathrm{~h}$ at $50^{\circ} \mathrm{C}$. After phenol/chloroform extraction, DNA was ethanol precipitated. DNA was then coiled around a sterile pipette tip, washed with $70 \%$ ethanol, dried under vacuum, and resuspended in $300 \mu \mathrm{l}$ of TE buffer $(10 \mathrm{mM}$ Tris- $\mathrm{HCl}, \mathrm{pH} 8.0$, and $1 \mathrm{mM}$ EDTA). Concentration of extracted DNA was determined by gel electrophoresis using high DNA Mass Ladder (Gibco Life Technologies, Paisley, UK) on $0.5 \%$ agarose gels.

Polymerase chain reaction amplification and sequencing of rDNA. rDNA analysis was carried out on the Venturia spp. reference strain isolates and a selection of the unidentified field isolates. Primers ITS5 (5'-GGAAGTAAAAGTCGTAACAAGG$\left.3^{\prime}\right)$ and ITS4 (5'-TCCTCCGCTTATTGATATGC- $\left.3^{\prime}\right)$ were used to amplify a DNA fragment from the $3^{\prime}$ end of the $18 \mathrm{~S}$ rRNA gene to the $5^{\prime}$ end of the $28 \mathrm{~S}$ rRNA gene (Fig. 1). These primers are universal primers complementary to conserved regions of fungal rRNA gene (44). Polymerase chain reaction (PCR) was performed in a total volume of $50 \mu \mathrm{l}$, containing $10 \mathrm{mM}$ Tris- $\mathrm{HCl}, \mathrm{pH} 8.3$, $50 \mathrm{mM} \mathrm{KCl}, 1.5 \mathrm{mM} \mathrm{MgCl} 2,100 \mu \mathrm{M}$ each of dATP, dCTP, dGTP, and dTTP, $0.15 \mu \mathrm{M}$ primers ITS4 and ITS5, $20 \mathrm{ng}$ of genomic DNA, and 0.5 units of Taq DNA polymerase (Gibco Life Technologies). Cycling conditions were modified from Tenzer and Gessler (41): $94^{\circ} \mathrm{C}$ for $2 \mathrm{~min}$, followed by 30 cycles of $94^{\circ} \mathrm{C}$ for $30 \mathrm{~s}, 54^{\circ} \mathrm{C}$ for $1 \mathrm{~min}$, and $72^{\circ} \mathrm{C}$ for $1 \mathrm{~min}$, and a final step of $72^{\circ} \mathrm{C}$ for $7 \mathrm{~min}$.

In addition, species-specific primers were designed, based on our own and published rDNA sequence data of $V$. inaequalis populations and other Venturia spp., to specifically amplify rDNA of $V$. asperata, $V$. carpophila, $V$. inaequalis, and V. pirina $(31,36)$. Species-specific primers Vina (5'-GTCTGAGAACAAGTTAAATAA-3'), Vpir (5'-GTCTGAGAACGAGTTAAAT-3'), Vasp (5'-GTCTGAGAAACAAGTAATAG-3'), and Vcar (5'-GTCTGAGGAGAAAGCCAANCG-3') are complementary to the noncoding ITS1 region of the rRNA gene for $V$. inaequalis, $V$. pirina, $V$. asperata, and V. carpophila, respectively (Fig. 1). These primers, in combination with primer ITS4, were designed to amplify DNA from the $3^{\prime}$ end of the ITS1 region to the $5^{\prime}$ end of the 28S rRNA gene of the corresponding species to give a PCR product of approximately $450 \mathrm{bp}$ in length. PCR reactions were performed in a total volume of $50 \mu \mathrm{l}$ containing 20 to $60 \mathrm{ng}$ of template DNA, $1 \mu \mathrm{M}$ species-specific primer or primer ITS4, $100 \mu \mathrm{M}$ each dATP, dCTP, dGTP, and dTTP, 0.5 units of Taq DNA polymerase, $20 \mathrm{mM}$ Tris- $\mathrm{HCl}, \mathrm{pH} 8.4$, and $50 \mathrm{mM} \mathrm{KCl}$, and $1.5 \mathrm{mM} \mathrm{MgCl}_{2}$. Cycling parameters were $94^{\circ} \mathrm{C}$ for $2 \mathrm{~min}$ followed by 30 cycles of $94^{\circ} \mathrm{C}$ for $30 \mathrm{~s}, 50^{\circ} \mathrm{C}$ for $1 \mathrm{~min}$, and $72^{\circ} \mathrm{C}$ for $1 \mathrm{~min}$, and a final step of $72^{\circ} \mathrm{C}$ for $7 \mathrm{~min}$.

Amplifications were performed in a GeneAmp PCR system (2400; Perkin-Elmer, Foster City, CA). Amplification products were analyzed by electrophoresis through $1.0 \%$ agarose in $1 \times$ Tris-borate-EDTA buffer. Ethidium bromide-stained gels were visualized with UV light (Geldoc 1000; Bio-Rad Laboratories, Hercules, CA).
The PCR products from amplifications with universal primers ITS4 and ITS5 of seven field isolates (representing the three different apple leaf sources) and two $V$. pirina ICMP reference strains were sequenced directly in both directions. PCR products were purified with the Qiagen kit (Qiagen, Hilden, Germany) and sequenced with the BigDye terminator kit (Perkin-Elmer, ABI Prism, Foster City, CA) according to the manufacturer's instructions at the Waikato University sequencing facility.

Sequences were checked visually on electropherograms produced by ABI Prism 377 sequence analysis software. Sequences were aligned using the pile up algorithm implemented within GCG (Genetics Computer Group, University Research Park, Madison) and modified by eye. Phylogenetic trees were constructed from aligned ITS1-5.8S-ITS2 sequence data with phylogenetic analysis using parsimony (PAUP 4.0; Sinauer Associates Inc., Champaign, IL). Neighbor joining on distance (Kimura 2 parameter) and parsimony (heuristic search, TBR) analyses were used for tree construction. Bootstrapping with 1,000 and 100 replicates was carried out for neighbor joining and parsimony trees, respectively, in order to estimate confidence limits of edges (15).

\section{RESULTS}

Ascospore discharge monitoring. Two types of Venturia ascospores (V. inaequalis and a second unidentified Venturia sp.) were observed on the exposed glass slides (Fig. 2). Both Venturia ascospore types were of similar dimensions and septate at approximately a third of their length. However, the widest point of the $V$. inaequalis ascospores was in the shorter of the two cells, whereas the widest point of the unidentified ascospores was always in the longer cell, with the shorter cell narrower and tapering (Fig. 2). The ascospores deposited on the slides were of variable appear-
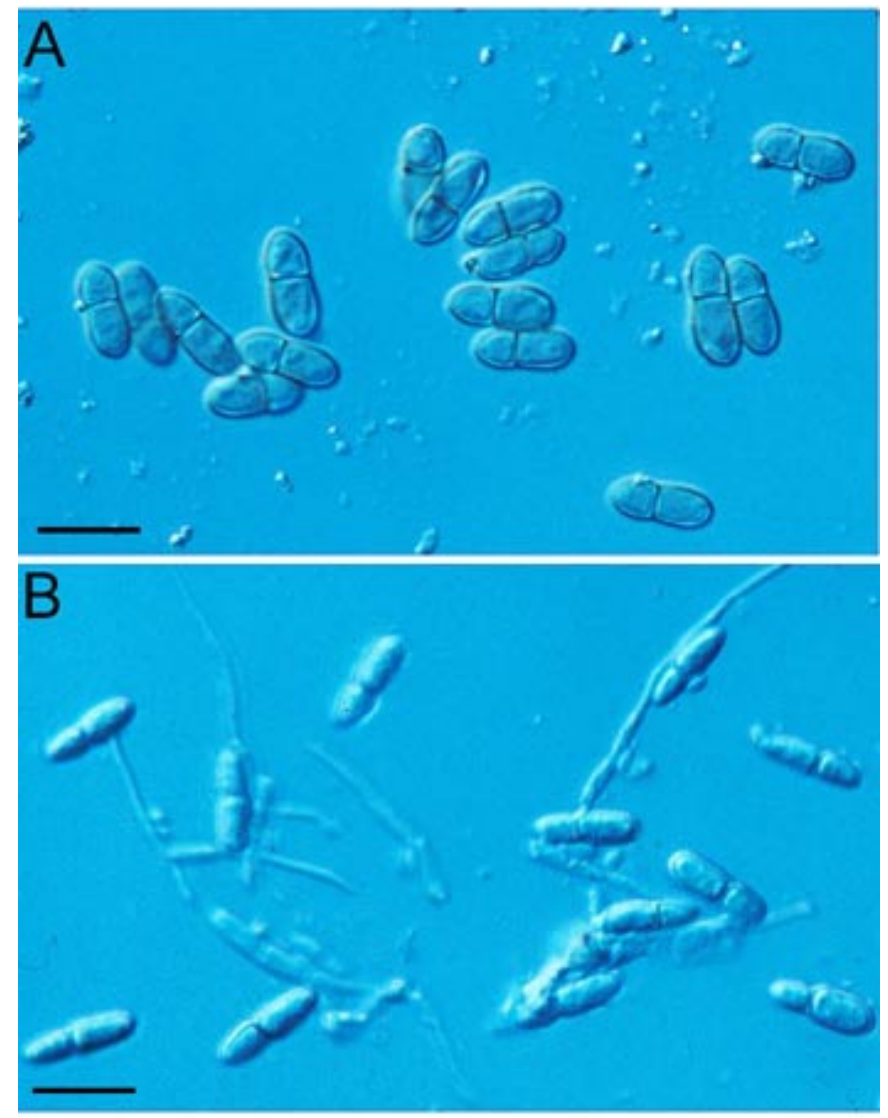

Fig. 2. Dehydrated ascospores trapped on microscope slides during ascospore monitoring: A, Venturia inaequalis (1998); and B, an unidentified Venturia sp. (1999). Spores were stained with lactophenol cotton blue and photographed by phase contrast microscopy. Scale bar $=15 \mu \mathrm{m}$. 
ance because of differing degrees of dehydration, overhydration, and germination, but the two species could be visually distinguished.

At the Gisborne, Nelson, and Central Otago sites, both ascospore types were trapped at most of the slide and transect positions on the leaf meshes (Table 1). On these slides, the two Venturia spp. appeared as alternating blocks (up to several millimeters in length) of a single ascospore type rather than a mixed deposit. At the Auckland site, there were moderately high counts of $V$. inaequalis ascospores but almost none of the unidentified Venturia sp. (data not shown). At the Hawkes Bay site, negligible spring rainfall resulted in very low counts of ascospores of either species.

Differences in the timing and magnitude of Venturia ascospore counts at Gisborne, Central Otago, and Nelson monitoring sites (Fig. 3) were associated with different frequencies and quantities of rainfall during the ascospore discharge period (total rainfall during the period: Gisborne $15.7 \mathrm{~mm}$; Central Otago $178.5 \mathrm{~mm}$; and Nelson $540.6 \mathrm{~mm}$ ). At these three sites, the ascospore counts of both $V$. inaequalis and the unidentified Venturia sp. exhibited a similar pattern of response to short term changes in the local weather. The relative magnitude of the $V$. inaequalis counts at the three sites clearly reflected the different site rainfalls, but the magnitude of the unidentified species counts was apparently less

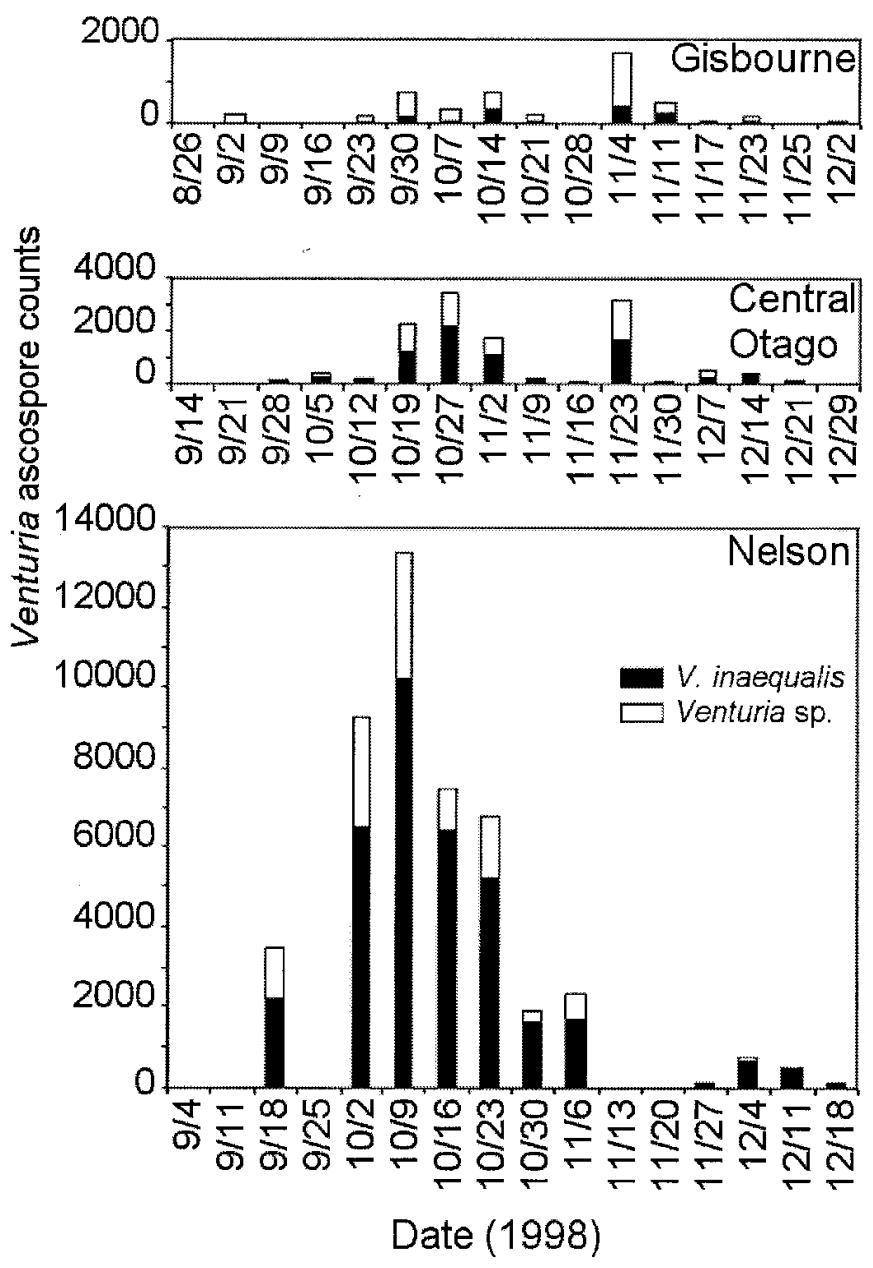

Fig. 3. Total counts of Venturia ascospores (V. inaequalis [black] and an unidentified Venturia sp. [white]), trapped by the exposed glass slide method from apple leaf litter at Gisborne (upper; 10 slides, 30 transects), Central Otago (middle; 15 slides, 45 transects), and Nelson (lower; 10 slides, 30 transects) apple growing districts, New Zealand, during spring 1998. The horizontal axes give the date of the end of the exposure period of each set of slides. The scales of the vertical axes have been adjusted to compensate for the different numbers of slides/transects at the three sites. affected by rainfall. Thus, the ratios between the counts of $V$. inaequalis and the unidentified species were always high at the high rainfall Nelson site; approximately 1:1 at the moderate rainfall Central Otago site; and always low at the low rainfall Gisborne site, where ascospores of the unidentified species predominated (Fig. 3).

Field isolations. Individual leaves bore pseudothecia of two different Venturia spp. readily distinguishable by the orientation of their ascospores within intact asci. Pseudothecia of $V$. inaequalis were widely distributed over the leaf surface and associated with visible scab symptoms. The ascospores were septate in the distal third, with the shorter distal cell wider than the longer proximal cell, i.e., the characteristic morphology of $V$. inaequalis ascospores. Pseudothecia of the second, unidentified Venturia sp. were more sparsely distributed and occurred only in patches where there were no scab symptoms and no pseudothecia of $V$. inaequalis. The ascospores of the unidentified species were septate in the proximal third, with the longer distal cell wider than the shorter, tapering proximal cell (Fig. 4A), similar to the morphology of the unidentified Venturia ascospores trapped on the monitoring slides. Single ascospores of the unidentified species were cultured on MEA. All 62 isolates produced conidia that were solitary or in short chains, the conidiogenous cell being sympodial, polyblastic, with old scars thickened and crowded, resulting in a nodular appearance (Fig. 4B). Although these characters accorded with descriptions of $V$. asperata, $V$. carpophila, or $V$. pirina, no definite identification was possible based on morphological characteristics alone.

rDNA analysis of Venturia spp. and universal primers, ITS4 and ITS5, reveal length polymorphisms. A PCR fragment of $926 \mathrm{bp}$ was produced by amplification with primers ITS4 and ITS5 of rDNA from $V$. inaequalis MNH 120 (Fig. 5) and from each of 51 single-spore isolates of $V$. inaequalis from various locations within NZ (31). rDNA fragments of reference strains of $V$. asperata, V. carpophila, and $V$. pirina were amplified with universal primers ITS4 and ITS5 and each had a size of approximately $540 \mathrm{bp}$ (Fig. 5). The length polymorphism in PCRamplified fragments between Venturia spp. and within populations of $V$. inaequalis was due to the presence of a 390-bp intron within the $18 \mathrm{~S}$ coding region, as revealed by sequence analysis. This intron has been identified as a group I intron based on characteristic border sequences (39). Amplification of rDNA from 20 of the unknown field strains resulted in fragments of approximately $540 \mathrm{bp}$ (data not shown). This indicated that the ascospores of the second unknown species were most probably not $V$. inaequalis, but of another Venturia sp.

Evaluation of species-specific primers. Species-specific primers were designed to specifically bind to rDNA of Venturia spp. at the $3^{\prime}$ end of the ITS1 region (Fig. 1). The species-specific primers designed in this study amplified rDNA of the corresponding species only, producing fragments of approximately $450 \mathrm{bp}$ when used with primer ITS4 (Fig. 5). rDNA of 20 field isolates, representing the three different ascocarps, were screened with these species-specific primers, and fragments of approximately $450 \mathrm{bp}$ were amplified with the $V$. pirina-specific primer only (Fig. 6). rDNA of these field isolates did not amplify with the $V$. inaequalis-

TABLE 1. Percentage of different slide and transect positions on apple leaf litter at which ascospores of Venturia inaequalis and an unidentified Venturia sp. were trapped by the exposed glass slide method at Gisborne (10 slides, 30 transects), Central Otago (15 slides, 45 transects), and Nelson (10 slides, 30 transects) apple growing districts, New Zealand, in spring 1998

\begin{tabular}{|c|c|c|c|c|c|c|}
\hline \multirow{2}{*}{$\begin{array}{l}\text { Ascospores } \\
\text { trapped }\end{array}$} & \multicolumn{2}{|c|}{ Gisborne } & \multicolumn{2}{|c|}{ Central Otago } & \multicolumn{2}{|c|}{ Nelson } \\
\hline & Slide & Transect & Slide & Transect & Slide & Transect \\
\hline$V$. inaequalis & 10 & 10 & 27 & 36 & 0 & 3 \\
\hline Venturia sp. & 0 & 3 & 0 & 0 & 0 & 0 \\
\hline Both & 90 & 87 & 73 & 64 & 100 & 97 \\
\hline
\end{tabular}


specific or any other of the species-specific primers (Fig. 6). This is a strong indication that the field isolates are $V$. pirina.

Interspecific variation in the ITS1-5.8S-ITS2 region. ITS15.8S-ITS2 sequences of $V$. pirina field isolates CSS 1.12, CSS 1.22, CSS 2.1, CSS 2.2, CSS 3.15, CSS 3.16, and CSS 3.17 were assigned GenBank Accession Nos. AF 333440 to AF 333446, respectively. GenBank Accession Nos. AF 333438 and AF 333439 were assigned to ITS1-5.8-ITS2 sequences of $V$. pirina isolates ICMP 11032 and ICMP 11033. The ITS1-5.8S-ITS2 sequences of V. asperata cultures ICMP 13990, ICMP 13991, ICMP 13992, and ICMP 13993 were assigned GenBank Accession Nos. AF 333450, AF 33449, AF 333447, and AF 333448, respectively.

ITS1-5.8S-ITS2 fragments amplified with primers ITS4 and ITS5 from the nine unidentified field strains and reference strains of V. pirina (ICMP 11032 and 11033) and V. asperata (ATCC 34052 and ICMP 13990 to 13993) were sequenced in both directions. The ITS1 and ITS2 regions of the unidentified field isolates tested in this study were 155 and $150 \mathrm{bp}$, respectively. The 5.8S DNA in all strains tested was 159 bp long. Phylogenetic analysis of the ITS regions and the 5.8S subunit from Venturia spp. sequenced in this study and recently published sequences (36) was performed using parsimony and distance analysis. Initially, rDNA sequence from Phaeocryptopus gaeumannii (AF
013225), a member of Venturiaceae, was used as an outgroup. This analysis revealed a monophyletic grouping of Cladosporium caryigenum (pecan scab pathogen), V. carpophila (peach scab pathogen), $V$. cerasi (cherry scab pathogen), and $V$. asperata (apple saprophyte). This monophyletic group was chosen as an appropriate outgroup in subsequent analysis of Venturia spp. pathogenic on pipfruit ( $V$. inaequalis, $V$. nashicola, and $V$. pirina).

Parsimony analysis grouped $V$. nashicola isolates (Mamenashi 12A1-1 and 12A1-3, from Japanese pear) separately from $V$. pirina isolates (supported by a weak bootstrap value, $52 \%$ ). Using distance analysis, V. nashicola clustered within the V. pirina (Fig. 7). ITS1-5.8S-ITS2 sequences from unknown field isolates clustered with NZ field isolates of $V$. pirina (97.9\% identity) and sequences published for $V$. pirina (97.6\% identity). Therefore, the ascospores of unknown identity isolated from apple leaf litter were positively identified as $V$. pirina. In our analysis, NZ isolates of $V$. pirina were closely related to $V$. pirina isolates Akita FB-1 from Japan, MPS8 from Michigan, and IL-4 from Israel and formed a separate group to $V$. pirina isolates IL-18 and IL-11 from Israel and the V. nashicola isolates (bootstrap value, 79\%). Amplified rDNA from NZ field isolates of $V$. pirina tested in this study showed a maximum divergence of $2.1 \%$. Maximum divergence between published sequences of overseas isolates and NZ
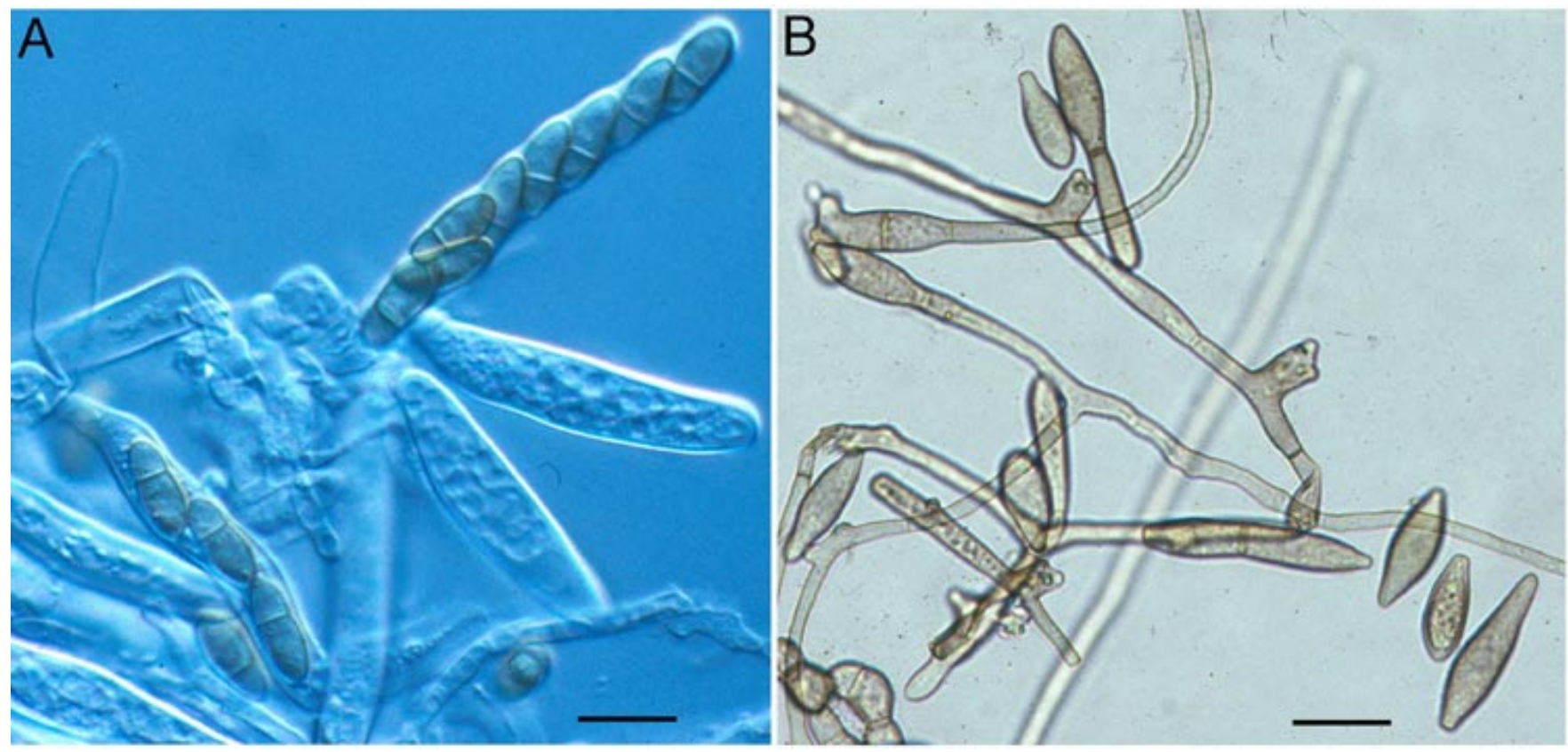

Fig. 4. A, Dissected ascus with ascospores of unknown field isolate from apple leaf litter visualized by phase contrast microscopy. B, Sporulation structures of an unknown field isolate (derived from a single ascospore) in culture on potato dextrose agar were stained with lactophenol cotton blue and visualized by bright field microscopy. Scale bar $=15 \mu \mathrm{m}$.

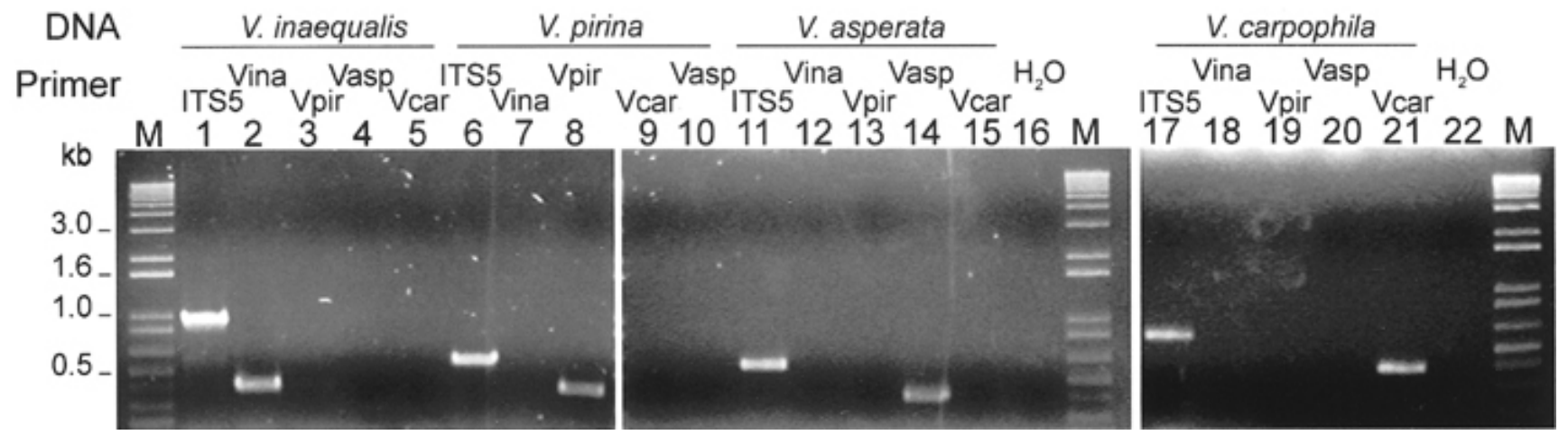

Fig. 5. Species-specific primers only amplified the DNA of the Venturia sp. for which they were designed (when used with internal transcribed spacer [ITS] primer ITS4). The size of ribosomal fragments polymerase chain reaction amplified from Venturia spp. By universal primers ITS4 and ITS5 varies. 
isolates of $V$. pirina was $2.8 \%$. This is similar to the level of divergence of published sequences from $V$. nashicola to that of $V$. pirina $(3.5 \%)$. Maximum divergence in rDNA sequences of the 51 $\mathrm{NZ}$ isolates of $V$. inaequalis was $1.5 \%$ (31).

ITS1-5.8S-ITS2 sequences of the four $V$. asperata ICMP isolates were identical to that published for $V$. asperata ATCC 34052. V. asperata is distinguished from the stone fruit pathogens (V. cerasi and V. carpophila) and supported by a bootstrap value of $100 \%$ (Fig. 7).

Pathogenicity of Venturia spp. on apple and pear. Infection studies were performed to determine pathogenicity of $V$. pirina field isolates collected in this study, using detached apple and pear leaves. Pear cv. Winter Nellis (open pollinated seedlings) was used because it was identified as the probable source of the ascospore field isolates from apple leaf litter that were identified as $V$. pirina. In pathogenicity assays on apple, $V$. inaequalis isolate MNH 120 was used as a positive control. In pathogenicity assays on pear, $V$. pirina isolate P3.1, known to infect pear cv. Winter Nellis, was used as a positive control.

Isolate $\mathrm{MNH} 120$ was able to infect detached apple leaves, resulting in macroscopically visible scab lesions 8 to 10 days after inoculation. Abundant formation of conidia, especially along the veins of infected leaves, indicated the successful establishment of infection (Fig. 8). Using UV-microscopy, autofluorescence (an indicator for a resistance response of the host to the pathogen) of plant cells upon infection with $V$. inaequalis MNH 120 was never detected (Fig. 8). In contrast, inoculation of apple leaves with conidia of the unknown field isolates did not result in establishment of successful infection and macroscopically visible symptoms. Conidia of the unknown isolates germinated successfully. Germ tubes produced appressoria and runner hyphae, which resulted in limited saprophytic growth on the leaf surface. Occasional sparse sporulation of $V$. pirina field isolates was detected although subcuticular structures were never detected. In rare instances ( $<5 \%$ of germinated fungal spores), single epidermal cells were fluorescing in association with appressoria of unknown field isolates (Fig. 8). In these circumstances, the growth was restricted to formation of germ tubes and appressoria, and further saprophytic growth of the fungus was prevented. This resistance reaction of the plant did not result in a macroscopically visible symptom.
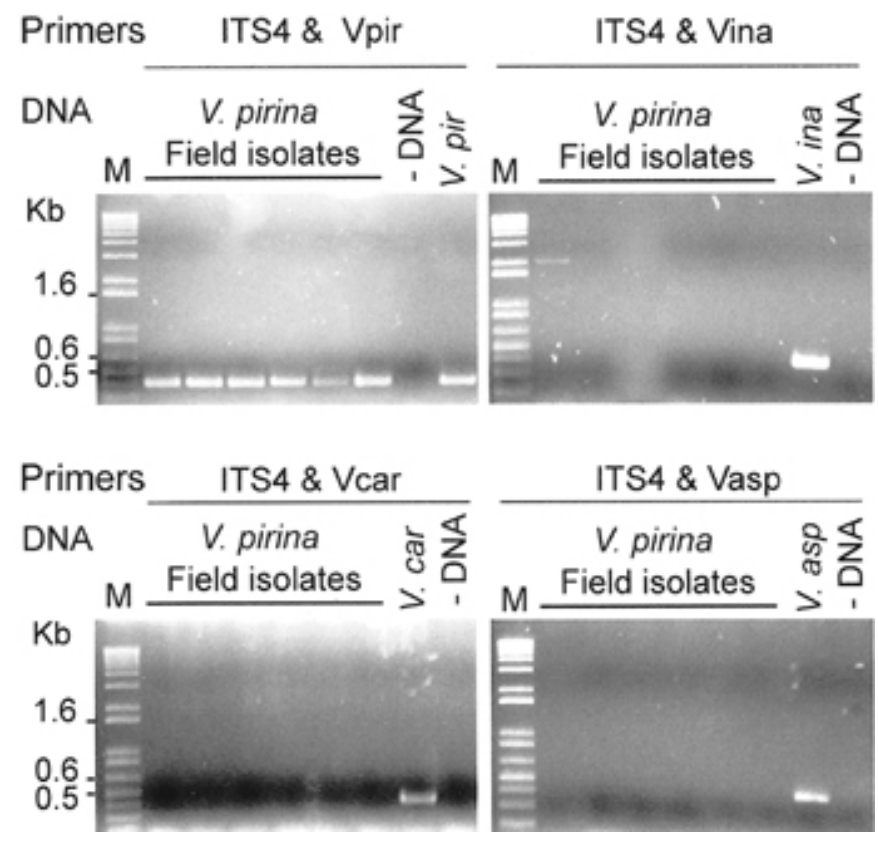

Fig. 6. DNA of the unknown Venturia sp. amplifies only with the $V$. pirina species-specific primer and universal internal transcribed spacer (ITS) primer ITS4.
Both $V$. pirina isolates, P3.1 and CSS 1.12, were able to infect detached pear leaves, resulting in visible scab lesions (data not shown). Using bright field light microscopy, abundant sporulation and extensive subcuticular growth confirmed the successful establishment of infection. Autofluorescence of pear cells in response to fungal invasion were never detected by UV microscopy.

\section{DISCUSSION}

In this study, ascospores of Venturia spp. that were isolated from apple leaf litter in addition to $V$. inaequalis, were identified as $V$. pirina on the basis of morphological characters and rDNA sequence analysis. Such ascospores have not been observed in 10 previous seasons by identical monitoring methodology and apple leaf litter from different sources (18 orchards; 6 apple cultivars in New Zealand). It is therefore plausible, that conditions peculiar to this particular litter source (an organic orchard with a history of zero usage of conventional modern fungicides) were associated with the occurrence of sexual reproduction of $V$. pirina on apple leaf litter. Ascospores of similar appearance to $V$. pirina were, however, detected in very low numbers in the following year (Fig. 2). Attempts to identify these ascospores directly from microscope slides with the PCR primers developed in this study were unsuccessful due to contamination with lactophenol cotton blue. Pear trees (cv. Winter Nellis) in the vicinity of the litter source block of 'Braeburn' apple trees were probably close enough to constitute a source of the $V$. pirina inoculum, but were unlikely to have contributed a direct deposition of pear leaves. The leaf litter meshes were assembled shortly after leaf fall, while apple and pear leaves were still readily distinguishable. Moreover, a high

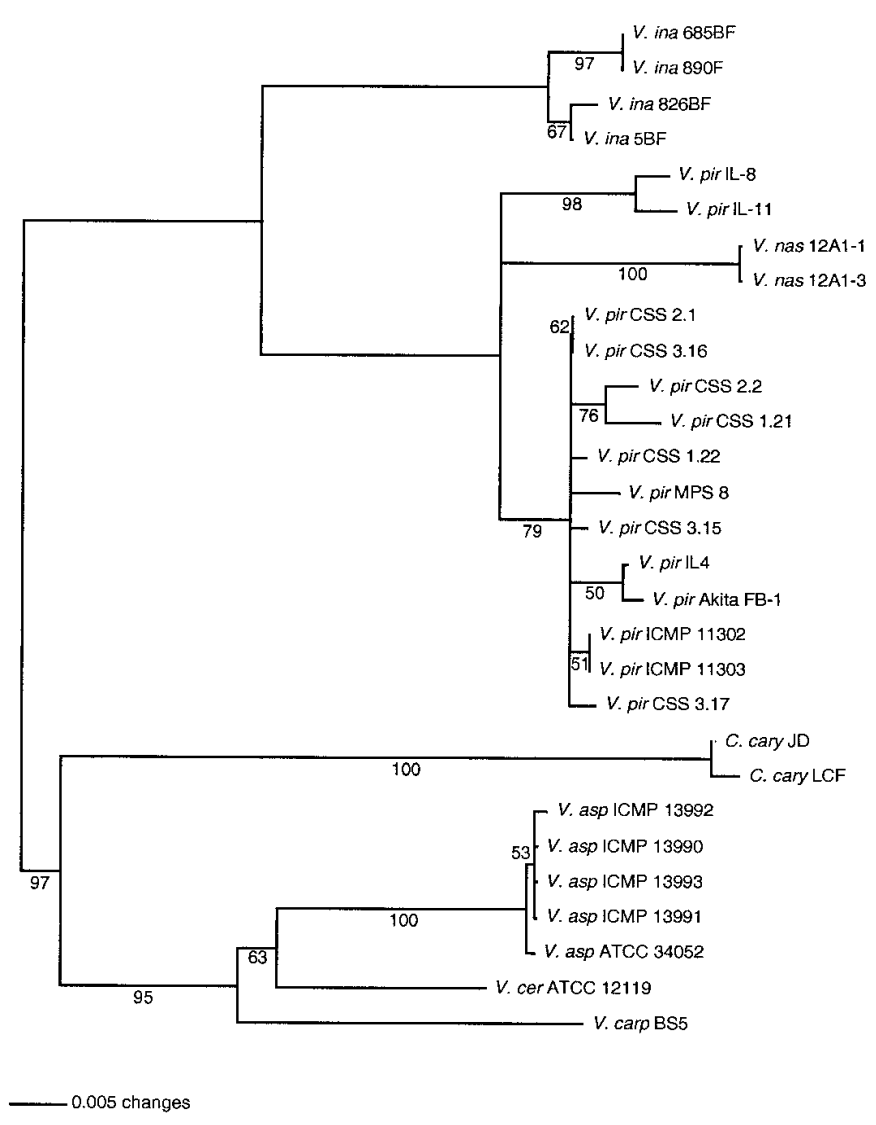

Fig. 7. Neighbor joining tree generated from Kimura 2 parameter distances among internal transcribed spacer (ITS) ITS1-5.8S-ITS2 DNA sequences from Venturia spp. and Cladosporium caryigenum isolates. Bootstrap values from 1,000 replicates over $50 \%$ are indicated. The tree is rooted using the $C$. caryigenum, V. asperata, V. cerasi, and V. carpophila clade. 
incidence of pear leaf "contamination" would have resulted in large homogeneous areas of $V$. pirina ascospores on the microscope slides rather than the observed mosaic of alternating patches of ascospores of the two species. The observation of pseudothecia of both, $V$. inaequalis and $V$. pirina, within individual leaves is direct evidence that this is a genuine phenomenon and not a contamination artifact.

Release of ascospores from $V$. inaequalis is dependent on climatic factors, mainly temperature during winter/spring, which influences maturation of ascospores, and daytime rainfall in spring, which affect the release of ascospores from mature asci $(5,16)$. Various prediction models have been based on these data (26). The data presented in this study have shown that ascospores of Venturia spp., which are nonpathogenic on apple, may be present in ascospore counts. In our study, the patterns of ascospore discharge were almost identical for $V$. inaequalis and $V$. pirina (Fig. 3). Thus, failure to distinguish between the two ascospore types would result in amplification of the ascospore counts, but no significant change in the relative pattern of discharge over time (which the exposed glass slide method is designed to monitor).

In this study, molecular techniques were successfully applied in the accurate identification of V. pirina, because species assignment based on host range and morphological features was insufficient. A complete rDNA sequence analysis proved that the unidentified Venturia spp. isolated from apple leaf litter was indeed $V$. pirina. Length polymorphisms within the rDNA of Venturia populations have been reported previously $(36,39,41)$. However, length variation due to the presence/absence of an intron in the $18 \mathrm{~S}$ coding region (recorded in all V. inaequalis NZ isolates (31) and absent from all other Venturia spp. to date) is not a reliable character for species identification, because the intron is not found in all $V$. inaequalis isolates worldwide $(36,39,41)$. Additionally, no length polymorphisms exist between $V$. asperata, $V$. carpophila, and $V$. pirina because they are all missing the intron and amplified a PCR product of 536 bp with universal primers ITS4 and ITS5. rDNA analysis, using sequence polymorphisms between Venturia spp. in the 18S and ITS1-5.8S-ITS2 regions, were applied previously in analysis of phylogenetic relationships within the Venturia spp. and were adequate for purposes of this study. rDNA sequence analysis revealed polymorphic regions within ITS1, to which species-specific primers were designed. The primers designed in this study have been shown to distinguish Venturia spp. from fruit trees reliably. However, to ensure the utility of the species-specific primers further screening of Venturia and other species would be required. It is not anticipated that the $V$. pirina-specific primer will be able to distinguish between $V$. pirina and $V$. nashicola isolates because these species are not polymorphic in this particular region of their rDNA (36). $V$. nashicola has not been recorded in NZ so far, therefore, no further analysis was performed to address this question.

Phylogenetic analysis, based on rDNA sequences, clustered the unknown field isolates with $V$. pirina NZ reference strains and published sequences for $V$. pirina isolates from other countries. Therefore, ascospores isolated from apple leaf litter in this study were reliably identified as $V$. pirina. rDNA sequence analysis indicated that the $V$. pirina population in $\mathrm{NZ}$ and elsewhere is highly polymorphic. A high level of rDNA polymorphism has also been demonstrated for $V$. inaequalis $(31,36,39,41)$. This is expected for species that reproduce sexually every disease cycle and have a large effective population size. These polymorphisms
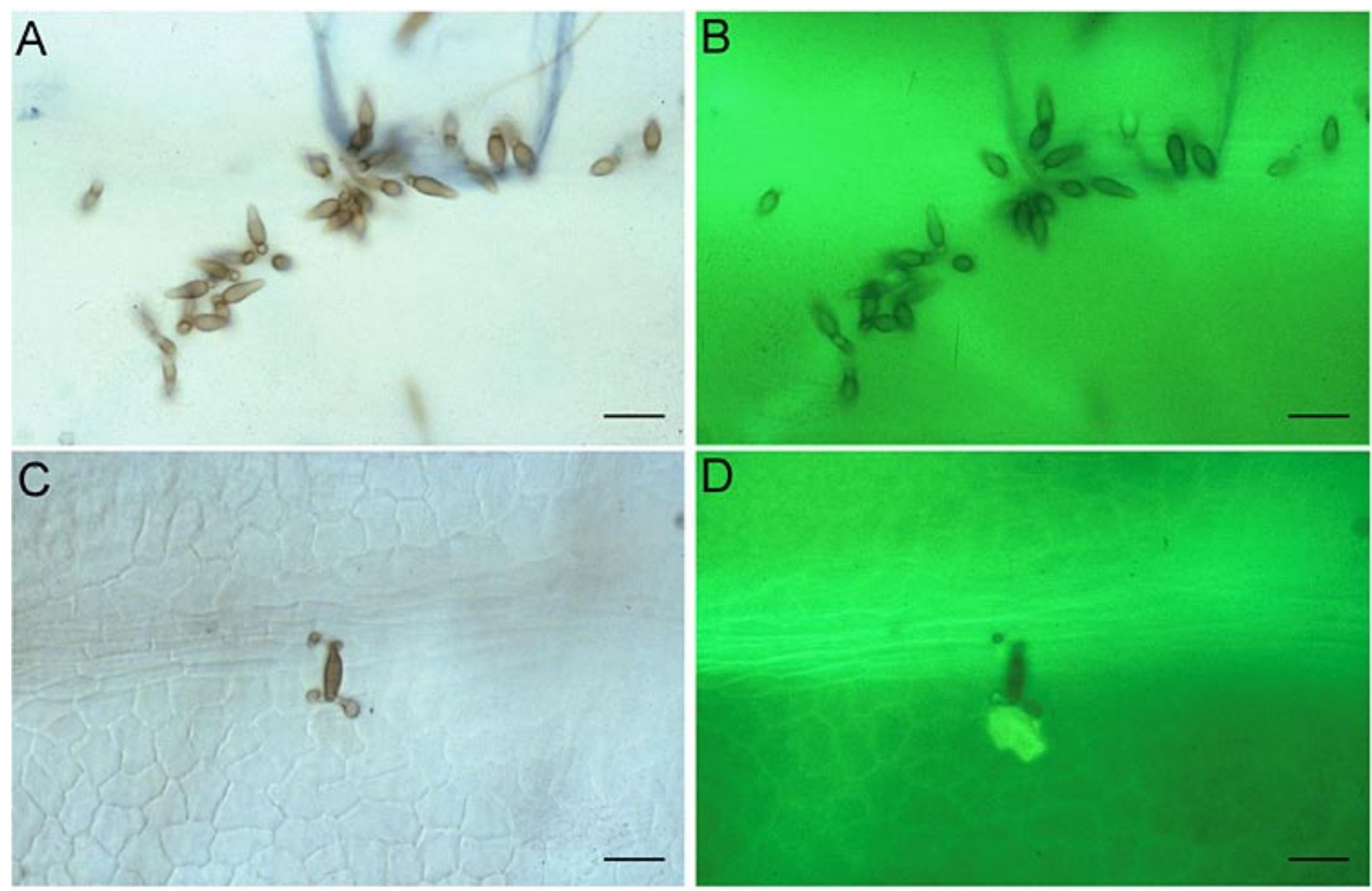

Fig. 8. A, Growth and sporulation of Venturia inaequalis isolate, MNH 120, on detached apple leaves by brightfield; and B, interference blue optics. C, $V$. pirina field isolate CSS1.22 germinated and produced appressoria on detached apple leaves (brightfield optics); and D, phenolic compounds that accumulated in single epidermal cell HR (associated with appressorium) show a bright autofluorescence when illuminated with UV (image taken with IB filter). Scale bar = $25 \mu \mathrm{m}$. 
within certain species can be useful characters for population genetics and other epidemiological studies. Amplified rDNA from $\mathrm{NZ}$ field isolates of $V$. pirina collected from apple leaf litter in 1998 showed a maximum divergence of $0.5 \%$, reflecting the fact that they were collected from a single location. Maximum divergence between published sequences of overseas isolates and NZ isolates of $V$. pirina was $2.8 \%$. This is in the same range of divergence of published sequences for $V$. nashicola and $V$. pirina (3.5\%) and supports the findings of Schnabel et al. (36) who reported these two species to be closely related and distinct from other Venturia fruit tree pathogens (maximum divergence between published sequences of $V$. pirina and $V$. inaequalis is $6.7 \%$; $V$. pirina and $V$. cerasi is 9.6\%; and V. pirina and V. carpophila is 9.9\%).

The only other Venturia sp. identified so far on apple is $V$. asperata $(9,35)$. V. asperata has only rarely been recorded, once in NZ and once in Canada $(9,35)$, and only five single ascospore isolates of this species were available for our studies, all collected in 1974 from a single leaf in NZ. In both reports, only sexually produced ascospores were isolated from apple leaf litter, and attempts to collect the anamorph (Fusicladium state) in spring/ summer were unsuccessful. Previous studies based on morphological characters and rDNA analysis suggested a close relationship of $V$. asperata with $V$. cerasi and $V$. carpophila $(35,36)$; however, accuracy of the phylogenetic relationships was limited due to low sampling number of both species. ITS1-5.8S-ITS2 sequences of additional ICMP isolates of $V$. asperata were identical with that of the ATCC isolate because they all originated from a single leaf. Therefore, no additional information is available on the evolutionary origin of this species. Studies on the pathogenicity of this species on rosaceous fruit trees have not been published, but it is assumed to be a saprophyte on apple. The results presented in this study confirm that occurrence of sexual fruiting bodies of hemibiotrophic fungi on a particular plant species should not be interpreted as direct evidence of pathogenicity. Further studies to elucidate host range of $V$. asperata within Rosaceae failed because the isolates have been in culture for decades and were no longer sporulating.

To our knowledge, this paper is the first report of $V$. pirina sexual structures on its nonhost, apple. Early cross-infection studies (28) reported that $V$. pirina is a pathogen of pear but is unable to infect apple, and $V$. inaequalis is a pathogen of apple but is unable to infect pear leaves. $V$. inaequalis infects some ornamental species of Rosaceae (e.g., Crataegus, Sorbus, and Cotoneaster); however, cross infection studies suggest that these isolates are better described as formae speciales (28). The hemibiotrophic nature of many Venturia spp. probably enables the saprophytic colonization of dead leaves of a range of plant species in the leaf litter. This may have implications for the cocultivation of related fruit tree species. Indeed, $V$. inaequalis grows saprophytically and produces pseudothecia on dead apple and pear leaf tissue that it could not infect successfully in living plants (34). The $V$. pirina field isolate (CSS 1.12) was shown to be highly pathogenic on open pollinated seedlings from Pyrus communis cv. Winter Nellis. This pear cultivar was growing in the adjacent block to the area where the apple leaf litter was collected and was probably the inoculum source for $V$. pirina isolated from the apple leaf litter. Our studies indicated that $V$. pirina can grow saprophytically on living apple tissue; however, it is not able to penetrate the apple cuticle and establish subcuticular hyphae for successful establishment of infection. In rare instances, hypersensitive response-like responses were detected by UV microscopy, in association with appressoria formation and termination of germ tube growth. These events may indicate the rare successful penetration of the nonhost cuticle. Thus, resistance in this nonhost may be due to both pre-existing defense mechanisms, such as cuticle composition and thickness, as well as the existence of specific recognition mechanisms, similar to host genotype resistance ( $\mathrm{R}$ genes) responses. These defense responses are in- active during leaf senescence/death, and thus, enable saprophytic colonization and sexual reproduction on the nonhost to occur.

A plant species unable to be successfully infected by all isolates of a pathogen species is generally defined as a nonhost for that pathogen species (20). This definition is generally accepted, but the mechanisms responsible for nonhost resistance continue to be a source of debate. Nonhost resistance was postulated to be due to multicomponent, physico-chemical barriers. In contrast, gene-forgene type resistance mechanisms of host species to races of a pathogen species (host-genotype resistance) are conferred by a single, major gene for resistance in the host (R gene) and a single gene in the pathogenic race mediating specific recognition. This ultimately results in hypersensitive plant cells death of resistant plant cells (13). The interaction between $V$. inaequalis and its host was one of the first plant-pathogen systems with good evidence for gene-for-gene interactions (4). In light of the growing body of evidence suggesting that major genes for resistance may also have an active role in nonhost resistance $(11,23,29,42,43)$, the observations of this paper warrant further investigation.

\section{ACKNOWLEDGMENTS}

This research was supported by the New Zealand Foundation for Research, Science and Technology contract 8080 . We thank R. Newcomb for phylogenetic analysis and R. Newcomb and R. M. Beresford for critical review of the manuscript.

\section{LITERATURE CITED}

1. Berbee, M. L., and Taylor, J. W. 1992. Two ascomycete classes based on fruiting body characters and ribosomal DNA sequences. Mol. Biol. Evol. 9:278-284

2. Beresford, R. M., and Spink, M. 1992. A national disease forecasting system for apple black spot (Venturia inaequalis) in New Zealand. Acta Hortic. ISHS 313:285-296.

3. Bishop, J. G., Dean, A. M., and Mitchell-Olds, T. 2000. Rapid evolution in plant chitinases: Molecular targets of selection in plant-pathogen coevolution. Proc. Natl. Acad. Sci. 97:5322-5327.

4. Boone, D. M., and Keitt, G. W. 1957. Venturia inaequalis (Cke.) Wint. XII Genes controlling pathogenicity of wild-type lines. Phytopathology 47:403-409.

5. Brook, P. J. 1969. Effects of light, temperature, and moisture on release of ascospores by Venturia inaequalis (Cke.) Wint. N. Z. J. Agric. Res. 12:214-227.

6. Bruns, T. D., White, T. J., and Taylor, J. W. 1991. Fungal molecular systematics. Annu. Rev. Syst. 22:525-564.

7. Bruzzese, E., and Hasan, S. 1983. A whole leaf clearing and staining technique for host specificity studies of rust fungi. Plant Pathol. 32:335338.

8. Campel, C. S., Donoghue, M. J., Baldwin, B. G., and Wojciechowski, M. F. 1995. Phylogenetic relationships in Maloideae (Rosaceae): Evidence from sequences of the internal transcribed spacers of nuclear ribosomal DNA and ITS congruence with morphology. Am. J. Bot. 83:903-918.

9. Corlett, M. 1984. Venturia asperata, a second species of Venturia occurring on apple in Canada. Page 235 in: The American Phytopathological Society and CPS Annual Meeting.

10. Crosby, J. A., Janick, J., Pecknold, P. C., Korban, S. S., O’Connor, P. A., Ries, S. M., Goffreda, J., and Voordeckers, A. 1992. Breeding apples for scab resistance: 1945-1990. Fruit Var. J. 46:145-166.

11. Crute, I. R. 1998. The elucidation and exploitation of gene-for-gene recognition. Plant Pathol. 47:107-113.

12. Cunningham, J. L. 1972. A miracle mounting fluid for permanent wholemounts of microfungi. Mycologia 64:906-911.

13. De Wit, P. J. G. M. 1992. Molecular characterization of gene-for-gene systems in plant-fungus interactions and the application of avirulence genes in control of plant pathogens. Annu. Rev. Phytopathol. 30:391-418.

14. Ellis, M. A., Ferree, D. C., Funt, R. C., and Madden, L. V. 1998. Effects of an apple scab-resistant cultivar on use patterns of inorganic and organic fungicides and economics of disease control. Plant Dis. 82:428-433.

15. Felsenstein, J. 1985. Confidence limits in phylogenies. An approach using the bootstrap. Evolution 39:783-791.

16. Gadoury, D. M., and MacHardy, W. E. 1982. Effects of temperature on the development of pseudothecia of Venturia inaequalis. Plant Dis. 66:464-468.

17. Geffroy, V., Sicard, D., de Oliveira, J. C., Sevignacad, M., Cohen, S., 
Gepts, P., Neema, C., Langin, T., and Dron, M. 1999. Identification of an ancestral gene cluster involved in the coevolution process between Phaseolus vulgaris and its fungal pathogen Colletotrichum lindemuthianum. Mol. Plant-Microbe Interact. 12:777-784.

18. Gessler, C. 1993. Biology and biotechnology in strategies to control apple scab. Norw. J. Agric. Sci. 17:337-353.

19. Gessler, C., and Blaise, P. 1994. Differential resistance in apple against scab and its use in breeding and orchard planting strategies to control the disease. Pages 99-104 in: Progress in Temperate Fruit Breeding. Vol. 1. H. Schmidt and M. Kellerhas, eds. Kluwer Academic Publishers, Dordrecht, the Netherlands.

20. Heath, M. C. 1985. Implications of nonhost resistance for understanding host-parasite interactions. Pages 25-42 in: Genetic Basis of Biochemical Mechanisms of Plant Disease. J. V. Groth and W. R. Bushnell, eds. The American Phytopathological Society, St. Paul, MN.

21. Hillis, D. M., and Dixon, M. T. 1991. Ribosomal DNA: Molecular evolution and phylogenetic interference. Q. Rev. Biol. 66:411-453.

22. Joosten, M. H. A. J., Cozijnsen, T. J., and de Wit, P. J. G. M. 1994. Host resistance to a fungal tomato pathogen is lost by a single base-pair change in an avirulence gene. Nature 367:384-386.

23. Kamoun, S., Huitema, E., and Vleeshowers, G. A. A. 1999. Resistance to oomycetes: A general role for the hypersensitive response? Trends Plant Sci. 4:196-200.

24. Koeller, W. 1994. Chemical control of apple scab-status quo and future. Norw. J. Agric. Sci. 17:149-170.

25. Liyanage, H. D., McMillan, R. T., Jr., and Kistler, H. C. 1992. Two genetically distinct populations of Colletotrichum gloeosporioides from citrus. Phytopathology 82:1371-1376.

26. MacHardy, W. E. 1996. Apple Scab: Biology, Epidemiology, and Management. The American Phytopathological Society, St. Paul, MN.

27. McDonald, B. A., McDermott, J. M., Allard, R. W., and Webster, R. K. 1989. Coevolution of host and pathogen populations in the Hordeum vulgare-Rhynchosporium secalis pathosystem. Proc. Natl. Acad. Sci. 86:3924-3927.

28. Menon, R. 1956. Studies on Venturiaceae on rosaceous plants. Phytopathol. Z. 27:117-146.

29. Newton, A. C., and Crute, I. H. 1989. A consideration of the genetic control of species specificity in fungal plant pathogens and its relevance to a comprehension of the underlying mechanisms. Biol. Rev. 64:35-50.

30. Parisi, L., Lespinasse, Y., Guillaumes, J., and Krüger, J. 1993. A new race of Venturia inaequalis virulent to apples with resistance due to the Vf gene. Phytopathology 83:533-537.

31. Paterson, J. M. 1998. Genetic variation between V. inaequalis isolates and between Venturia species. M.S. thesis. University of Auckland, New Zealand.
32. Pederson, W. L., and Leath, S. 1988. Pyramiding major genes for resistance to maintain residual effects. Annu. Rev. Phytopathol. 26:369378.

33. Rohe, M., Gierlich, A., Hermannm, H., Hah, M., Schmidt, B., Rosahl, S., and Knogge, W. 1995. The race-specific elicitor, NIP1, from the barley pathogen, Rhynchosporium secalis, determines avirulence on host plants of the Rrs1 resistance genotype. EMBO J. 14:4168-4177.

34. Ross, R. G., and Hamlin, S. A. 1965. Production of perithecia of Venturia inaequalis (Cke.) Wint. on sterile apple leaf discs. Can. J. Bot. 43:959-965.

35. Samuels, G. J., and Sivanesan, A. 1975. Venturia asperata and its Fusicladium state on apple leaves. N. Z. J. Bot. 13:645-652.

36. Schnabel, G., Schnabel, E. L., and Jones, A. L. 1999. Characterization of ribosomal DNA from Venturia inaequalis and its phylogenetic relationship to rDNA from other tree-fruit Venturia species. Phytopathology 89: 100-108.

37. Sivanesan, A. 1977. The taxonomy and pathology of Venturia species. Bibliotheca Mycologica, J. Cramer, Vaduz, Liechtenstein.

38. Sivanesan, A., and Waller, J. M. 1974. CMI Descriptions of Pathogenic Fungi and Bacteria. Commonw. Mycol. Inst./Assoc. Appl. Biol., Kew, Surrey, England.

39. Tabrett, A. M., Roberts, A. L., and Barbara, D. J. 1997. Proceedings of 4 th workshop on integrated control of pome. IOBC/WPRS Bull. 20:217220.

40. Tartarini, S., Gianfranceschi, L., Sansavini, S., and Gessler, C. 1999. Development of reliable PCR markers for the selection of the $V f$ gene conferring scab resistance in apple. Plant Breed. 118:183-186.

41. Tenzer, I., and Gessler, C. 1997. Subdivision and genetic structure of four populations of Venturia inaequalis in Switzerland. Eur. J. Plant Pathol. 103:565-571.

42. Tosa, Y. 1992. A model for the evolution of formae speciales and races. Phytopathology 82:728-730.

43. Vleeshouwers, V. G. A. A., van Dooijeweert, W., Govers, F., Kamoun, S., and Colon, L. T. 2000. The hypersensitive response is associated with host and nonhost resistance to Phytophthora infestans. Planta 210:853864.

44. White, T. J., Bruns, T., Lee, S., and Taylor, J. 1990. Amplification and direct sequencing of fungal ribosomal RNA genes for phylogenetics. Pages 315-322 in: PCR Protocols: A Guide to Methods and Applications. M. A. Innis, D. H. Gelfand, J. J. Sninsky, and T. J. White, eds. Academic Press, Sand Diego, CA.

45. Yap, E. P. H., and McGee, J. O. D. 1991. Slide PCR: Amplification from cell samples on microscopic slides. Nucleic Acids Res. 19:4294.

46. Yoder, O. C. 1988. Cochliobolus heterostrophus, cause of southern corn leaf blight. Adv. Plant Pathol. 6:93-122. 